\title{
Analysis of Geographically Anomalous 2019 Novel Coronavirus Transmission in China
}

\author{
Yixiao Li1,2*, Zhaoxin Dai1 \\ ${ }^{1}$ Chinese Academy of Surveying and Mapping, Beijing, China \\ ${ }^{2}$ Beijing No.4 High School International Campus, Beijing, China \\ Email: ^18710071303@126.com, daizx@lreis.ac.cn
}

How to cite this paper: Li, Y.X. and Dai, Z.X. (2020) Analysis of Geographically Anomalous 2019 Novel Coronavirus Transmission in China. Journal of Geographic Information System, 12, 96-111. https://doi.org/10.4236/jgis.2020.122006

Received: March 5, 2020

Accepted: April 7, 2020

Published: April 10, 2020

Copyright (c) 2020 by author(s) and Scientific Research Publishing Inc. This work is licensed under the Creative Commons Attribution International License (CC BY 4.0).

http://creativecommons.org/licenses/by/4.0/

(c) (i) Open Access

\begin{abstract}
Approximately in the late-December of 2019, the coronavirus disease outbreak took place in China. COVID-19 (Coronavirus Disease 2019) is contagious and detrimental to the human body, which can even lead to death. As a result, the understanding of COVID-19 has become especially important. This paper studies four cases of anomalous disease-spreading in China (Guangdong Province, Heilongjiang province, Tianjin municipality, and Guizhou province) and analyzes four influencing factors of the transmission (temperature, transportation and passenger traffic volume, household size and distribution, and awareness). Major conclusions in this paper are as follows. Transportation and passenger traffic volume and the number of larger households are positively related to the extent of disease-spreading; the degree of awareness is negatively associated with the extent of disease-spreading. Provinces, municipalities, and autonomous regions with a more urbanized distribution of households are prone to experience a greater extent of disease transmission. Although the novel coronavirus prefers colder environment, temperature appears to be a secondary influencing factor, as regions with negative temperatures have fewer diagnoses. Disease transmission in Guangdong province is caused by a high volume of passenger traffic, large and urbanized households, and low awareness. Heilongjiang province is mainly a result of high passenger traffic volume, long travelling trips, and low public awareness. Guizhou province is benefited from high awareness, limited passenger volume, and scattered households. Tianjin municipality is protected from the severe disease-spreading owe to its beneficial temperature, low land transportation volume, and high public and government awareness.
\end{abstract}

\section{Keywords}

COVID-19, Disease Transmission, Geographically Anomalous Cases, Factor Analysis 


\section{Introduction}

In the Late-December of 2019, the novel coronavirus outbreak took place in Wuhan City, Hubei province, China. Coronavirus disease is officially named by the World Health Organization as COVID-19 (Coronavirus Disease 2019) on 12th January 2020. It can result in influenza, or even Middle East Respiratory Syndrome and Severe Acute Respiratory Syndrome. Currently, it is commonly believed that COVID-19 is caused by the sale and consumption of bats. Since December 2019, coronavirus disease has spread through relocation diffusion and contagious diffusion from the center, Wuhan city.

The existing literature on contagious disease outbreak is mainly based on the researching of the pathology of novel coronavirus and drug development [1] [2], epidemic prediction [3], and disease transmission [4] [5]. Among the analysis of disease transmission, most are concentrated on assessing the potential of human-to-human transmission. As this conclusion is now verified, less study, however, focused on researching influencing factors that affect trends of disease transmissions. Additionally, while the existing papers based their study areas on the center of the outbreak, Wuhan City, or on China as a whole, fewer papers have concentrated on minor provinces or municipalities that experienced an anomalous transmission. Therefore, this research will study four provinces (Heilongjiang province, Guangdong province, Guizhou province, Tianjin municipality) that experience an anomalous disease-spreading (that is, disease-spreading does not influence by geographical locations to the center) from 21st January 2020 to 19th February 2020, and analyzes the four influencing factors (temperature, transportation and passenger traffic volume, urban planning, and policy-making and individual consciousness) with respect to transmission. This paper will provide helpful guidance for disease prevention and control in the capital city of China, Beijing, other cities and countries across the world, and for future copings with similar contagious diseases.

The paper is organized as follows. Section 2 presents past literature on disease transmission and their characteristics. Section 3 introduces the data sources and methodology. Section 4 presents and analyzes the influencing factors for anomalous disease-spreading in four provinces. Section 5 discusses plausible suggestions for disease control and prevention in Beijing, and concludes the paper.

\section{Literature Review}

Most papers at present have focused on researching disease transmission. In particular, Riou et al. studied transmission patterns and the potential for sustained human-to-human transmission of 2019-nCoV in China [6]. According to Lin et al., public health interventions implemented at both the social and personal levels are effective in preventing outbreaks of COVID-19 in Wuhan and the other 29 provinces in China [7]. Based on 41 cases of 2019-nCoV in Wuhan City, Tang et al. find out that intensive contact tracing followed by quarantine and isolation can effectively reduce the control reproduction number and transmission risk [8]. 
The existing literature has mostly pinpointed their study areas in China as a whole. Fewer studies have narrowed down their focus on provinces and regions that experience anomalous disease-spreading (transmitting trends in provinces, municipalities, autonomous regions that are not influenced by geographical locations to the center). In addition, these studies put less focus on analyzing other influencing factors, such as government and residential awareness, temperature, passenger traffic volume, and household size and distribution. Thus, this paper is going to focus on studying four influencing factors in four provinces that manifested anomalous disease-spreading geographically.

\section{Data Source and GIS Tools}

\subsection{Data Source}

The data of accumulated confirmed cases of 2019-nCoV comes from Jinritoutiao (Today's Headlines) APP by 19th February 2020 in all provinces/municipalities/ autonomous regions in China mainland. The data of passenger traffic volume, number of large households, household distribution, and temperature derived from 2019 China yearbook, which reflects the statistics in 2018. We assume that the general rankings and trends of development for each influencing factor did not change significantly in 2019. For temperature, we adopted the average value in provincial capitals to represent the overall value in each province for correlation analysis. In addition, all the correlation analysis has eliminated the statistics of an obvious outlier, Hubei province. The research utilizes Python language in calculating the mean and ranking the statistics

\subsection{GIS Tools}

TIANDITU is a map website of China, which provides official free web mapping services. It features detailed street-level geographic data for China, and it is constructed and maintained by the National Geomatics Center of China (NGCC). This paper adopts the GIS Functions in TIANDITU (https://www.tianditu.gov.cn/) to gauge the distance between different province/municipality/autonomous regions and Wuhan City, China. Thus, this study derives regions that experience geographically anomalous disease spreading.

ArcGIS is a geographic information system (GIS) software for creating and editing maps and compiling and analyzing geographic data. This research visualizes the extent of confirmed coronavirus disease in each province/municipality/ autonomous region in China mainland through ArcGIS. Confirmed cases are divided into seven intervals when presenting on maps in different colors, respectively 1 - 15, 15 - 60, 60 - 99, 99 - 499, 499 - 999, 999 - 4999, >4999 (unit: case).

\section{Results}

\subsection{Determination of Anomalous Cases}

Table 1 displays the confirmed cases (volume from more to less), and Figure 1 illustrates the spatial distribution of confirmed diagnoses. According to Table 1, 
Table 1. Statistics of confirmed cases in each province/municipality/autonomous region by 19 th Feb. 2020.

\begin{tabular}{|c|c|}
\hline Province/Municipality/Autonomous Region & Confirmed Cases \\
\hline Hubei & 62,457 \\
\hline Guangdong & 1332 \\
\hline Henan & 1265 \\
\hline Zhejiang & 1175 \\
\hline Hunan & 1010 \\
\hline Anhui & 987 \\
\hline Jiangxi & 934 \\
\hline Jiangsu & 631 \\
\hline Chongqing & 560 \\
\hline Shandong & 546 \\
\hline Sichuan & 520 \\
\hline Heilongjiang & 476 \\
\hline Beijing & 395 \\
\hline Shanghai & 333 \\
\hline Hebei & 307 \\
\hline Fujian & 293 \\
\hline Guangxi & 245 \\
\hline Shanxi & 242 \\
\hline Yunnan & 172 \\
\hline Hainan & 168 \\
\hline Guizhou & 146 \\
\hline Shanxi & 131 \\
\hline Tianjin & 130 \\
\hline Liaoning & 121 \\
\hline Jilin & 91 \\
\hline Gansu & 91 \\
\hline Xinjiang & 76 \\
\hline Nei Mongol & 75 \\
\hline Ningxia & 71 \\
\hline Qinghai & 18 \\
\hline Xizang & 1 \\
\hline
\end{tabular}

confirmed cases of the novel coronavirus disease are extensively concentrated in Hubei province, with 62,457 cases by 19th February. Figure 1 further reveals that geographical locations influences disease-spreading significantly. In 


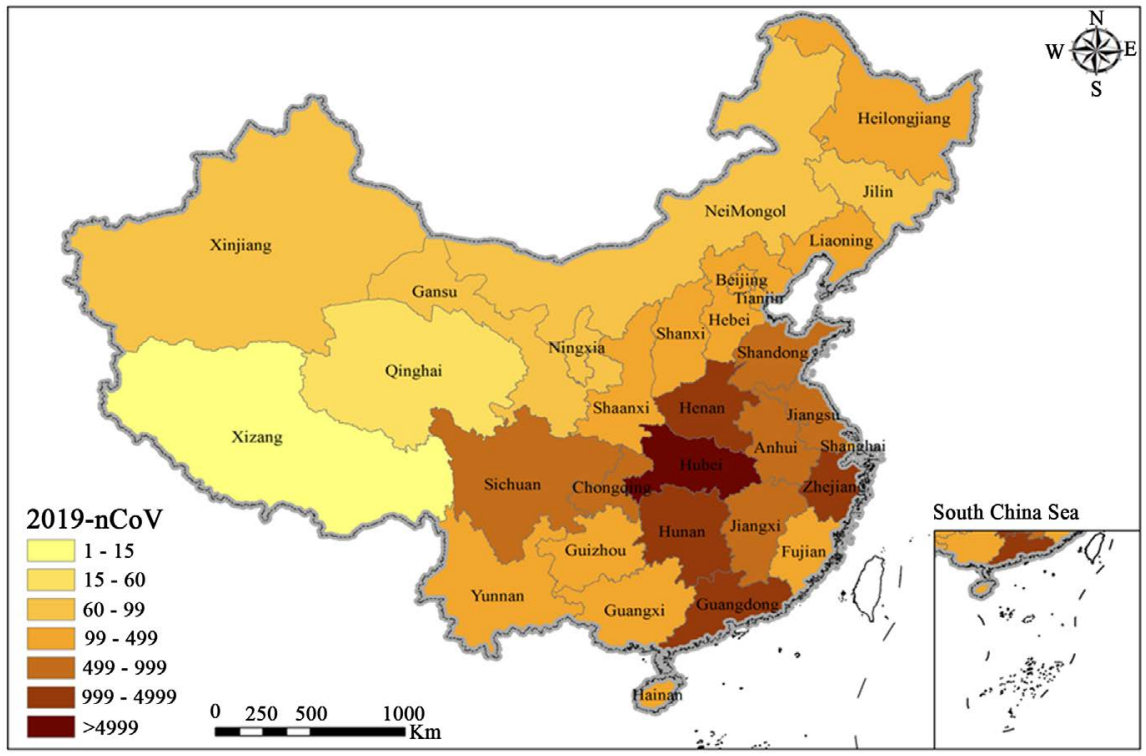

Figure 1. Spatial distribution of confirmed cases in China mainland by 19th February 2020.

particular, the top rankings mostly located within $600 \mathrm{~km}$ from Hubei Province: Henan province is approximately $467 \mathrm{~km}$ apart; Zhejiang province is about 562 $\mathrm{km}$ apart; Hunan province is around $297 \mathrm{~km}$ apart. However, in some provinces, geographical location remains one of the least influencing factors on disease-spreading. Guizhou province, in the proximity of Hubei, does not experience a remarkable outbreak of disease; Tianjin municipality, where people in Wuhan can easily arrive to for its developed railroad and highways, does not suffer greatly from coronavirus disease as well; Guangdong province and Heilongjiang province, situated more than $1000 \mathrm{~km}$ apart from Hubei province, has a large amount of confirmed diagnosis. Therefore, this paper will take these anomalous cases of disease-spreading into account and study the influencing factors that lead to the anomalies.

\subsection{Case 1: Guangdong Province}

\subsubsection{Transportation and Passenger Traffic Volume}

Table 2 and Figure 2 show the statistics and relationship between the number of confirmed cases and the passenger traffic volume in each province. Accordingly, the flow of population and the number of confirmed diagnoses have a moderately strong, approximately linear, positive correlation. Although Guangdong locates far from Hubei, it is one of the most developed provinces in China, with advanced transportation center at the mouth of the Pearl River and the largest seaport in southern China. Guangdong ranked top one in its passenger traffic volume (1,421,440 million people) in 2018. This results in Guangdong becoming a susceptible region to contagious diseases. Especially during the Spring Festival, the massive flow of population led to interaction and exchange between suspected cases and the public, resulting in the high confirmed cases in Guangdong. 


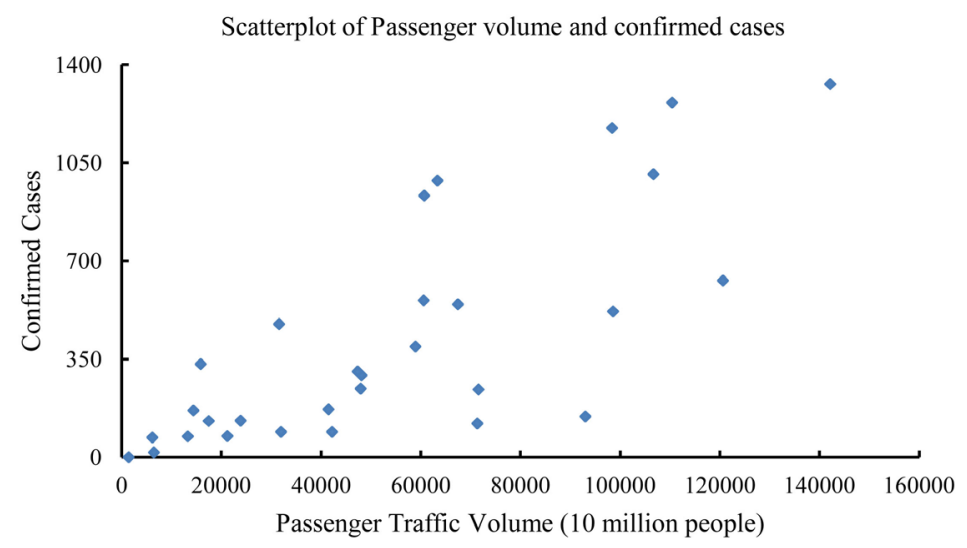

Figure 2. Scatterplot of the passenger traffic volume and number of confirmed cases in each province/municipality/autonomous region by 19th Feb. 2020.

Table 2. Statistics of passenger traffic volume and number of confirmed cases in each province/municipality/autonomous region (sorted according to passenger traffic volume).

\begin{tabular}{|c|c|c|}
\hline $\begin{array}{l}\text { Province/Municipality/ } \\
\text { Autonomous Region }\end{array}$ & $\begin{array}{c}\text { Passenger Traffic Volume } \\
\text { (10 Million) }\end{array}$ & $\begin{array}{l}\text { Confirmed } \\
\text { Cases }\end{array}$ \\
\hline Guangdong & 142,144 & 1332 \\
\hline Jiangsu & 120,612 & 631 \\
\hline Henan & 110,421 & 1265 \\
\hline Hunan & 106,680 & 1010 \\
\hline Sichuan & 98,569 & 520 \\
\hline Zhejiang & 98,380 & 1175 \\
\hline Guizhou & 93,025 & 146 \\
\hline Shaanxi & 71,583 & 242 \\
\hline Liaoning & 71,343 & 121 \\
\hline Shandong & 67,443 & 546 \\
\hline Anhui & 63,347 & 987 \\
\hline Jiangxi & 60,686 & 934 \\
\hline Chongqing & 60,587 & 560 \\
\hline Beijing & 58,935 & 395 \\
\hline Fujian & 48,105 & 293 \\
\hline Guangxi & 47,931 & 245 \\
\hline Hebei & 47,346 & 307 \\
\hline Gansu & 42,185 & 91 \\
\hline Yunnan & 41,484 & 172 \\
\hline Jilin & 31,956 & 91 \\
\hline Heilongjiang & 31,568 & 476 \\
\hline Shanxi & 2383 & 131 \\
\hline Xinjiang & 21,204 & 76 \\
\hline Tianjin & 17,450 & 130 \\
\hline Shanghai & 15,845 & 333 \\
\hline Hainan & 14,383 & 168 \\
\hline Nei Mongol & 13,268 & 75 \\
\hline Qinghai & 6443 & 18 \\
\hline Ningxia & 6137 & 71 \\
\hline Xizang & 1399 & 1 \\
\hline
\end{tabular}




\subsubsection{Temperature}

Figure 3 illustrates the correlation between average temperature of January and February and confirmed cases in each province/municipality/autonomous region. Accordingly, there is no relationship between confirmed cases and the temperature warmer than 0 degrees Celsius. For regions that are colder than 0 degrees Celsius, the low temperature is accompanied with low diagnoses. Besides Heilongjiang (an anomalous case), none of the provinces/municipalities/ autonomous regions with negative temperatures have more than 400 confirmed cases. Although the novel coronavirus prefers colder environment, temperature appears to be a secondary influencing factor of 2019-nCoV transmission. According to the data in Table 3, Guangdong's temperature ranked the top two among China. Based on the relationships illustrated in the scatterplot, Guangdong turns out to have a higher number of confirmed cases.

Table 3. Statistics of temperature and confirmed cases in each province/municipality/ autonomous region by 19th February 2020.

\begin{tabular}{|c|c|c|}
\hline $\begin{array}{l}\text { Province/Municipality/ } \\
\text { Autonomous Region }\end{array}$ & $\begin{array}{l}\text { Average Temp. of Jan. and Feb. } \\
\text { (Degrees Celsius) }\end{array}$ & $\begin{array}{l}\text { Confirmed } \\
\text { Cases }\end{array}$ \\
\hline Hainan & 17.4 & 168 \\
\hline Guangdong & 13.8 & 1332 \\
\hline Guangxi & 13.7 & 245 \\
\hline Fujian & 11.4 & 293 \\
\hline Yunnan & 9.65 & 172 \\
\hline Chongqing & 8.75 & 560 \\
\hline Jiangxi & 6.70 & 934 \\
\hline Sichuan & 6.00 & 520 \\
\hline Hunan & 5.65 & 1010 \\
\hline Guizhou & 5.15 & 146 \\
\hline Zhejiang & 5.10 & 1175 \\
\hline Shanghai & 4.80 & 333 \\
\hline Jiangsu & 3.40 & 631 \\
\hline Anhui & 3.25 & 987 \\
\hline Xizang & 2.90 & 1 \\
\hline Henan & 2.55 & 1265 \\
\hline Shaanxi & 1.90 & 242 \\
\hline Shandong & 0.850 & 546 \\
\hline Hebei & -0.450 & 307 \\
\hline Beijing & -2.05 & 395 \\
\hline Tianjin & -2.40 & 130 \\
\hline Shanxi & -3.25 & 131 \\
\hline Ningxia & -5.00 & 71 \\
\hline Qinghai & -6.75 & 18 \\
\hline Gansu & -7.10 & 91 \\
\hline Nei Mongol & -9.80 & 75 \\
\hline Liaoning & -10.7 & 121 \\
\hline Xinjiang & -12.7 & 76 \\
\hline Jilin & -13.9 & 91 \\
\hline Heilongjiang & -17.9 & 476 \\
\hline
\end{tabular}




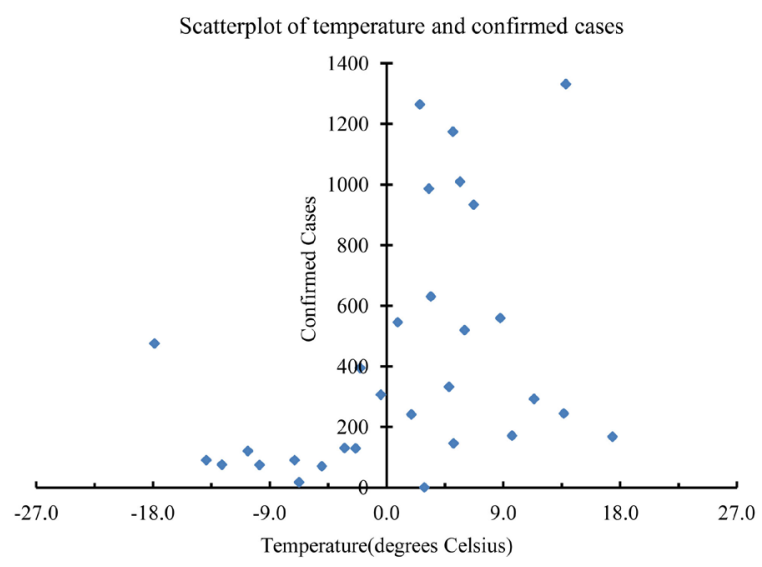

Figure 3. Scatterplot of temperature and confirmed cases in each province/municipality/ autonomous region by 19th February 2020.

\subsubsection{Household Size and Distribution}

Figure 4 illustrates the correlation between the number of medium- and large-sized households and the accumulated confirmed cases in each province/municipality/ autonomous region in China mainland by 19th February 2020. There is a moderately strong, positive, approximately linear correlation. Since members within each household have close contact with each other every day, the larger families, the higher the possibility for infectious people to transmit 2019-nCoV to a broader group. Table 4 shows the statistics of medium- and large-sized households in each province. There are 17,860 million families that have more than two members in Guangdong. In this case, it is prone for Guangdong to have a greater scope of disease-spreading than other provinces.

Figure 5 indicates the correlation between the number of urbanized population and confirmed cases. As implied in the scatterplot, there is a moderately strong, positive, approximately linear correlation between the two variables. Urbanized population displays a more concentrated residential distribution compared to rural population. A denser distribution of people is linked with increased contacts between individuals, resulting in a higher risk of contagion. Guangdong has 80,220 million households that live in urban areas, ranking the first. This correlates to Guangdong's 1332 cases of diagnosis, as shown in Table 5.

\subsubsection{Awareness}

Figure 6 indicates, at the very beginning stage of coronavirus outbreak, a significant rate of increase in Guangdong compared to the other three provinces examined in this paper. This shows that Guangdong's government and the public lacked serious awareness for disease control, which causes a large amount of confirmed diagnosis in later stages (in February).

\subsection{Case 2: Tianjin Municipality}

\subsubsection{Transportation and Passenger Traffic Volume}

Tianjin is located at the Bohai Bay in the Great Plains of North China. It has the 
The scatterplot between numbers of medium-sized and large-sized household and confirmed cases

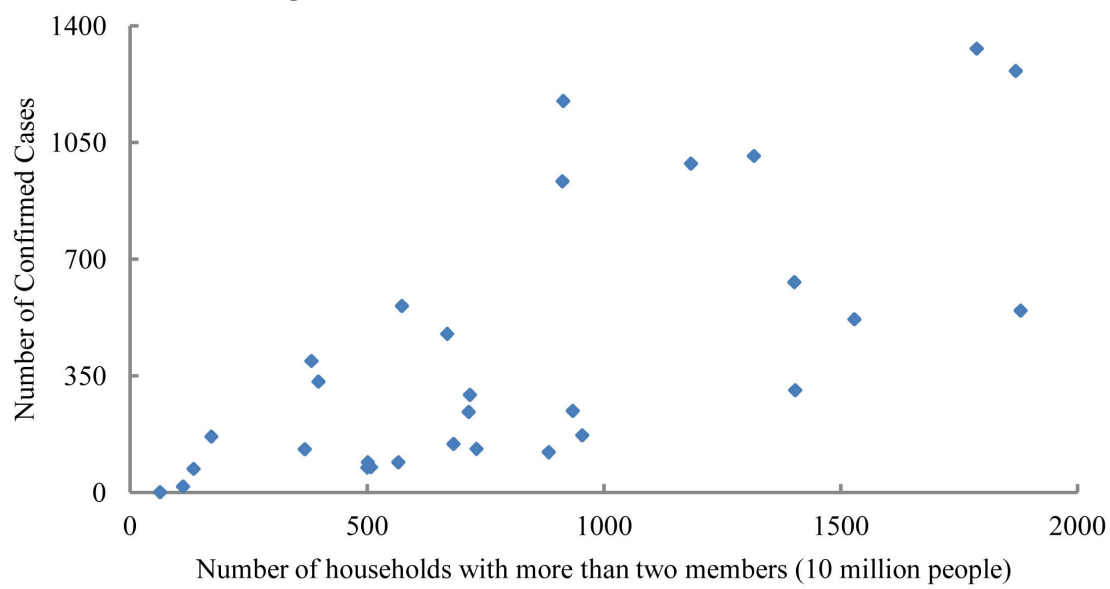

Figure 4. Scatterplot of medium- and large-sized households and confirmed cases in each provinces from 21 st January to 19th February.

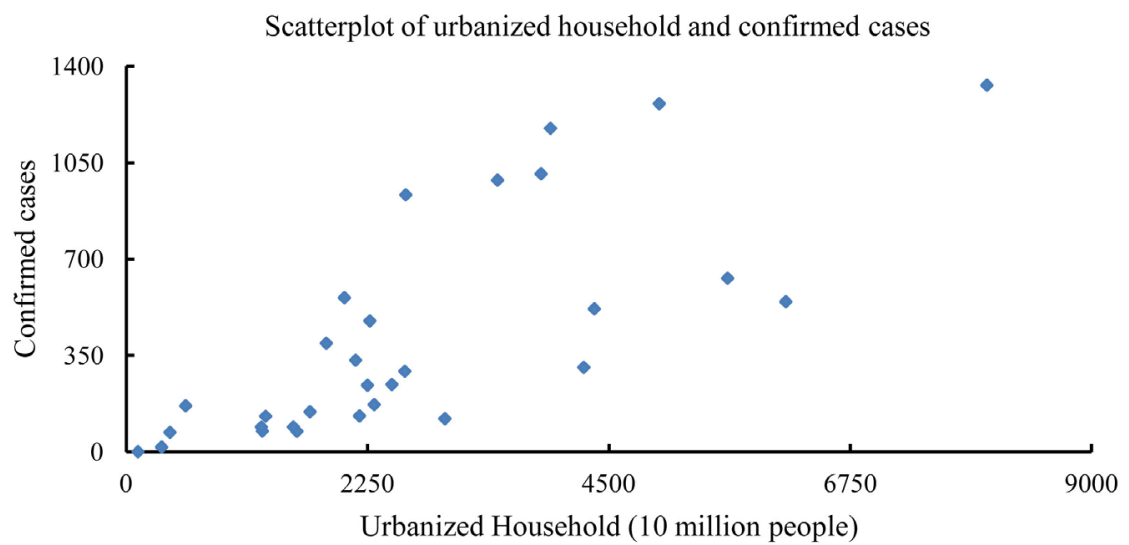

Figure 5. Scatterplot of the number of urbanized household and confirmed cases in each province/municipality/autonomous region by 19th February 2020.

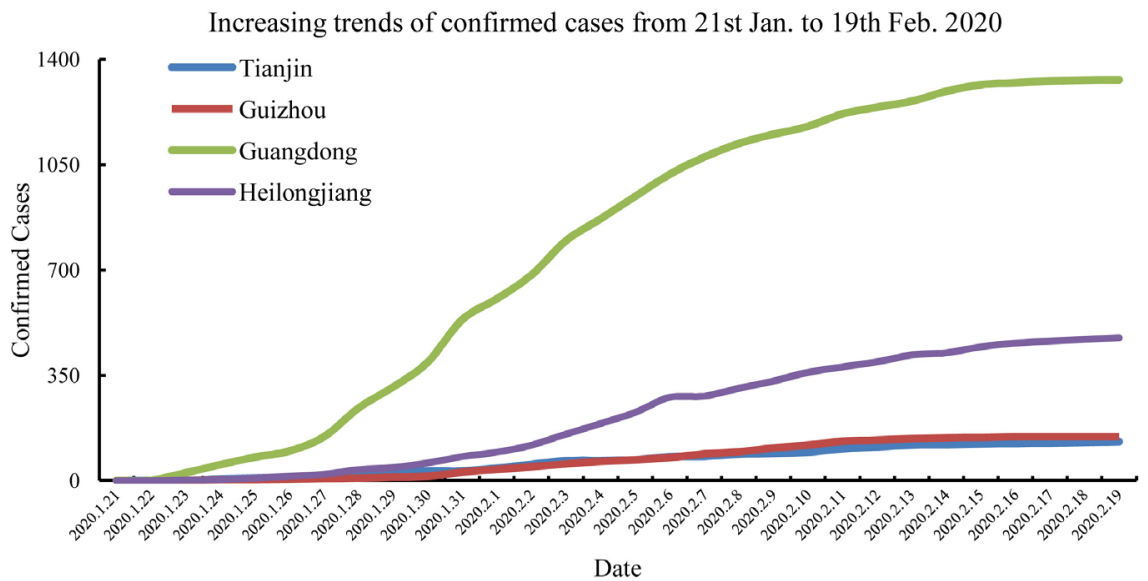

Figure 6. Increasing trends of confirmed cases in Tianjin municipality, Guizhou province, Guangdong province, and Heilongjiang province from 21st January to 19th February 2020 . 
Table 4. Statistics of medium- and large-sized households and confirmed cases in each province from 21st January to 19th February.

\begin{tabular}{|c|c|c|}
\hline $\begin{array}{l}\text { Province/Municipality/ } \\
\text { Autonomous Region }\end{array}$ & $\begin{array}{l}\text { Number of medium- and large-sized } \\
\text { household (10 million people) }\end{array}$ & $\begin{array}{l}\text { Confirmed } \\
\text { Cases }\end{array}$ \\
\hline Shandong & 1879 & 546 \\
\hline Henan & 1869 & 1265 \\
\hline Guangdong & 1786 & 1332 \\
\hline Sichuan & 1528 & 520 \\
\hline Hebei & 1403 & 307 \\
\hline Jiangsu & 1401 & 631 \\
\hline Hunan & 1316 & 1010 \\
\hline Anhui & 1183 & 987 \\
\hline Yunnan & 954 & 172 \\
\hline Guangxi & 934 & 245 \\
\hline Zhejiang & 913 & 1175 \\
\hline Jiangxi & 912 & 934 \\
\hline Liaoning & 883 & 121 \\
\hline Shanxi & 730 & 131 \\
\hline Fujian & 717 & 293 \\
\hline Shaanxi & 714 & 242 \\
\hline Guizhou & 682 & 146 \\
\hline Heilongjiang & 669 & 476 \\
\hline Chongqing & 573 & 560 \\
\hline Jilin & 565 & 91 \\
\hline Xinjiang & 508 & 76 \\
\hline Gansu & 501 & 91 \\
\hline Nei Mongol & 500 & 75 \\
\hline Shanghai & 397 & 333 \\
\hline Beijing & 382 & 395 \\
\hline Tianjin & 368 & 130 \\
\hline Hainan & 171 & 168 \\
\hline Ningxia & 133 & 71 \\
\hline Qinghai & 111 & 18 \\
\hline Xizang & 62 & 1 \\
\hline
\end{tabular}

largest seaport and water and land transportation facilities in northern China. Nevertheless, transportation at Tianjin is mainly constituted of maritime shipping and transporting activities with less population flow, as indicated above in Table 2. Therefore, Tianjin has successfully controlled the spread of disease. 
Table 5. Statistics of urbanized household and confirmed cases in each province/municipality/ autonomous region by 19th February 2020.

\begin{tabular}{|c|c|c|}
\hline $\begin{array}{l}\text { Province/Municipality/ } \\
\text { Autonomous Region }\end{array}$ & $\begin{array}{l}\text { Number of urbanized household } \\
\text { (10 million people })\end{array}$ & $\begin{array}{l}\text { Confirmed } \\
\text { Cases }\end{array}$ \\
\hline Guangdong & 8022 & 1332 \\
\hline Shandong & 6147 & 546 \\
\hline Jiangsu & 5604 & 631 \\
\hline Henan & 4967 & 1265 \\
\hline Sichuan & 4362 & 520 \\
\hline Hebei & 4264 & 307 \\
\hline Zhejiang & 3953 & 1175 \\
\hline Hunan & 3865 & 1010 \\
\hline Anhui & 3459 & 987 \\
\hline Liaoning & 2968 & 121 \\
\hline Jiangxi & 2604 & 934 \\
\hline Fujian & 2594 & 293 \\
\hline Guangxi & 2474 & 245 \\
\hline Yunnan & 2309 & 172 \\
\hline Heilongjiang & 2268 & 476 \\
\hline Shaanxi & 2246 & 242 \\
\hline Shanxi & 2172 & 131 \\
\hline Shanghai & 2136 & 333 \\
\hline Chongqing & 2032 & 560 \\
\hline Beijing & 1863 & 395 \\
\hline Guizhou & 508 & 76 \\
\hline Nei Mongol & 501 & 91 \\
\hline Jilin & 500 & 75 \\
\hline Tianjin & 397 & 333 \\
\hline Xinjiang & 382 & 395 \\
\hline Gansu & 368 & 130 \\
\hline Hainan & 171 & 168 \\
\hline Ningxia & 133 & 71 \\
\hline Qinghai & 111 & 18 \\
\hline Xizang & 62 & 1 \\
\hline
\end{tabular}

\subsubsection{Temperature}

Tianjin locates in the Beijing-Tianjin-Hebei region, the northern part of China. The average temperature during January and February in Tianjin is -2.4 degrees Celsius. With a lower-than-0-degrees-Celsius temperature, Tianjin has fewer cases of confirmed 2019-nCoV. 


\subsubsection{Awareness}

During the disease outbreak, Tianjin has carried out "Implementation measures during coronavirus disease outbreak for promoting economic and social development" early in time. As illustrated in Figure 7, at the very beginning stage, Tianjin has a slow rate of increase in confirmed cases per day. Additionally, the Jinyun application has shared detailed trip information of diagnosed patients to inform residents about ongoing situations efficiently. As indicated in Figure 8, Tianjin has the lowest number of diagnoses within the Beijing-Tianjin-Hebei region: the confirmed cases in Beijing and Hebei province are about 3 to 4 times of those in Tianjin. This underscores that the government control through on-time policy-making and the update of detailed patients' information has been especially critical for disease prevention and control.

\subsection{Case 3: Guizhou Province}

\subsubsection{Transportation and Passenger Traffic Volume}

According to Table 2, the population traffic volume of Guizhou is 930,250 million people in 2018, ranking in the top ten. However, during the outbreak, the heavy snow forced Guizhou to close roads and airport runways, which dissuades population movement and reduces the spread of disease.

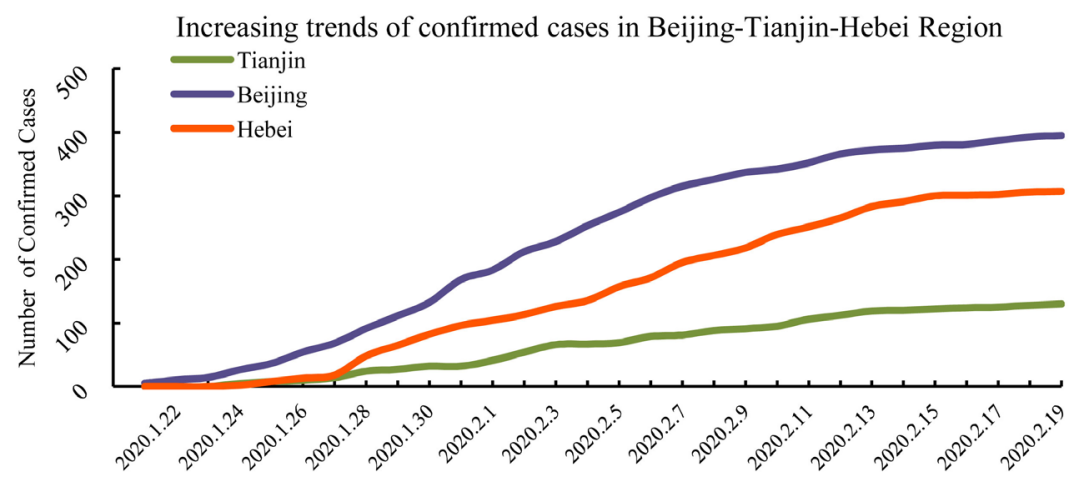

Figure 7. Increasing trends of confirmed cases in Beijing-Tianjin-Hebei region from 21st January to 19th February 2020.

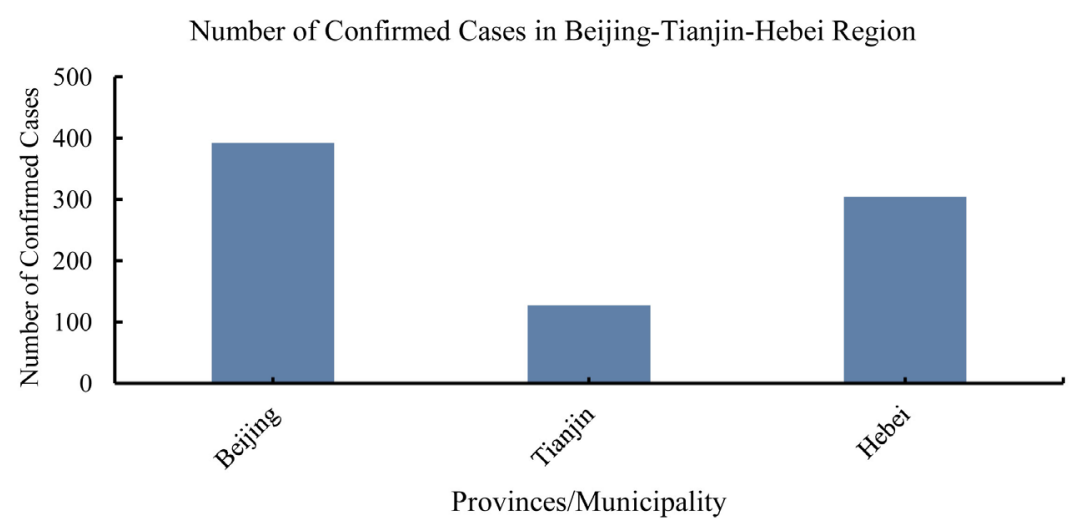

Figure 8. Number of confirmed cases in Beijing-Tianjin-Hebei region by 19th February 2020 . 


\subsubsection{Household Size and Distribution}

Guizhou is mainly constituted of mountainous, located at the Yungui Plateau. This reduces population density and concentration. In light of Table 4 and Table 5, Guizhou Province has only 6820 million urbanized households and 5080 million large households. The geography of Guizhou results in less urbanized residential concentrations and more scattered city arrangement across the provinces. Thus, the coronavirus cannot spread out easily.

\subsubsection{Awareness}

Guizhou province has carried out five pieces of implementation measures to strengthen disease control: first, identify suspected cases from data; second, verify their detailed profile; third, acquire their daily routine and mobility information; fourth, strictly ask for following report of their condition; fifth, restricted suspected cases from inflowing into Guizhou [9]. According to a detailed news report in Beijing Evening News, Guizhou has security officers collecting information about individuals' mobility and body temperature [10]. In addition, Guizhou has subsidized small and medium-sized enterprises to ensure their steady development during work extension. The high government awareness is conducive to disease control.

\subsection{Case 4: Heilongjiang Province}

\subsubsection{Transportation and Passenger Traffic Volume}

Though according to Table 2, the passenger traffic volume is 315,680 million people in Heilongjiang, ranking low, its Northern location makes Heilongjiang prone to infection. Trips to Heilongjiang are longer than those to other provinces, which increases the potential exposure to the virus and suspected cases. This further increases the possibility of infection, resulting in more confirmed cases in Heilongjiang.

\subsubsection{Temperature}

Heilongjiang is located in the very northern part of China with an average outdoor temperature of -17.9 degree Celsius during January and February. The freezing weather dissuades people from room ventilations. Especially when people congregated, the indoor and enclosed areas make disease-spreading easier, causing a significant increase in diagnosis.

\subsubsection{Awareness}

Heilongjiang's policies and control are not so strict as Tianjin and Guizhou. Heilongjiang did not suffer from the outbreak of SARS in 2003, and neither the government institutions nor residents have taken timely measures and control during the 2019 outbreak of the novel coronavirus. The mobility information of infected people did not expose in time. The public has not taken high regard for self-isolation. According to Sohu news, 94 percent of cases of infection are due to indoor congregation in Heilongjiang [11]. Furthermore, in accordance with Figure 9, Heilongjiang has 4 to 5 times of confirmed cases than Liaoning and 


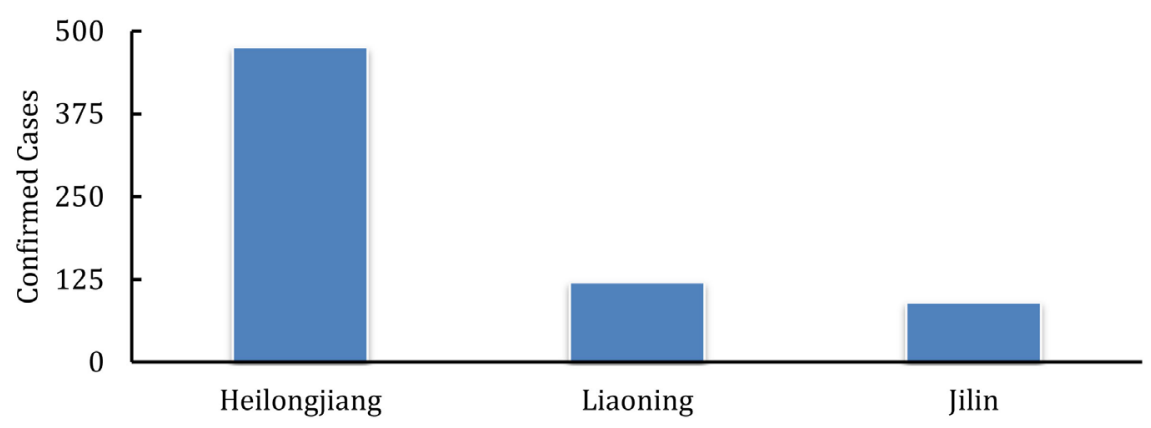

Figure 9. Confirmed cases in provinces in Northeastern China by 19th February 2020.

Jilin (Liaoning and Jilin have a similar geographical location as Heilongjiang, far from Hubei).

\section{Discussions and Conclusions}

This paper has studied the disease outbreak by 19th February 2020 in provinces and municipalities that experienced anomalous disease-spreading. Guangdong and Heilongjiang province have an unusually high quantity of confirmed diagnoses, whereas Tianjin municipality and Guizhou province are protected from a massive coronavirus transmission. This study focuses on four influencing factors that can account for these anomalies and obtains the following results. Transportation and passenger traffic volume and residential distribution and size are positively related to the extent of disease-spreading; the degree of government and individual consciousness has a negative correlation with disease-spreading. Although the novel coronavirus prefers colder environment, temperature appears to be a secondary influencing factor of 2019-nCoV transmission in this study, as regions with negative temperatures have fewer diagnoses. Disease transmission in Guangdong province is caused by the high volume of passenger traffic, large and urbanized households, and low awareness. Heilongjiang province is mainly a result of high passenger traffic volume, long travelling trips, and low public awareness. Guizhou province is benefited from high awareness, limited passenger volume, and scattered households. Tianjin municipality is protected from the severe disease-spreading owe to its beneficial temperature, low land transportation volume, and high public and government awareness.

Based on the results mentioned above, this paper will provide some suggestions for Beijing's disease control and prevention. As a well-developed municipality and the center of political and cultural activities, Beijing deserves more attention, or it will affect a series of more regions.

According to the positive cases of disease control in Tianjin municipality and Guizhou province, this paper proposes the followings for the Beijing government and community officers. 1) Beijing government should take high regard for disease control. For example, it should try best to limit the population inflow on-time. It should also carry out policies like verifying the identities of drivers 
and passengers at traffic stations carefully, to avoid infected people from entering Beijing. 2) For communities, officers should keep detailed track of mobility and information of incoming visitors and residents.

However, as the capital of China, Beijing has a more complex procedure in its policy-making and implementation. So, at the same time, a higher awareness in public will be helpful for disease reduction, or Beijing may undergo a similar negative situation as Heilongjiang province. This paper further advises the public as follows. 1) Individual residents should reduce congregating activities and self-isolate at home. 2) For organizations and institutions, less congregating events should be held during the outbreak to reduce the possibility of wider 2019-nCoV transmission.

The shortcomings of this paper are, first, with increasing data in the future, this paper can conduct more accurate analysis; second, in the future study, this paper can adopt complex approaches and regressing methodologies to test correlations and to study disease transmission.

\section{Author Contributions}

Y.L.: conceptualization, data processing, formal analysis, writing original draft, writing review and editing; Y.L. and Z.D.: visualization.

\section{Conflicts of Interest}

The authors declared no conflicts of interest.

\section{References}

[1] Cao, Y. (2020) Suggestion Using Ethanol Vaporization Killing Novel Coronavirus in the Lungs. https://doi.org/10.2139/ssrn.3513705

[2] Li, Y., Zhang, J., Wang, N., et al. (2020) Therapeutic Drugs Targeting 2019-nCoV Main Protease by High-Throughput Screening.

https://doi.org/10.1101/2020.01.28.922922

[3] Read, J.M., Bridgen, J.R.E., Cummings, D.A.T., et al. (2020) Novel Coronavirus 2019-nCoV: Early Estimation of Epidemiological Parameters and Epidemic Predictions. https://doi.org/10.1101/2020.01.23.20018549

[4] Li, Q., Guan, X., Wu, P., et al. (2020) Early Transmission Dynamics in Wuhan, China, of Novel Coronavirus-Infected Pneumonia. New England Journal of Medicine.

[5] Nishiura, H., Jung, S.-M., Linton, N.M., Kinoshita, R., Yang, Y., Hayashi, K., Kobayashi, T., Yuan, B. and Akhmetzhanov, A.R. (2020) The Extent of Transmission of Novel Coronavirus in Wuhan, China. Journal of Clinical Medicine, 9, 330. https://doi.org/10.3390/jcm9020330

[6] Riou, J. and Althaus, C.L. (2020) Pattern of Early Human-to-Human Transmission of Wuhan 2019 Novel Coronavirus (2019-nCoV), December 2019 to January 2020. Eurosurveillance, 25, 2000058. https://doi.org/10.2807/1560-7917.ES.2020.25.4.2000058

[7] Ralph, R., Lew, J., Zeng, T., et al. (2020) 2019-nCoV (Wuhan Virus), a Novel Coronavirus: Human-to-Human Transmission, Travel-Related Cases, and Vaccine Readiness. The Journal of Infection in Developing Countries, 14, 3-17. 
https://doi.org/10.3855/jidc.12425

[8] Tang, B., Wang, X., Li, Q., et al. (2020) Estimation of the Transmission Risk of the 2019-nCoV and Its Implication for Public Health Interventions. Journal of Clinical Medicine, 9, 462. https://doi.org/10.3390/jcm9020462

[9] Tongren City Government. Guizhou Province Issues 5 Measures to Strengthen Prevention and Control. http://www.trs.gov.cn/xwzx/trsyw/202001/t20200128_45686187.html

[10] Beijing Evening News. https://www.takefoto.cn/viewnews-2036594.html

[11] Sohu Website. http://www.sohu.com/a/371358141_349336 